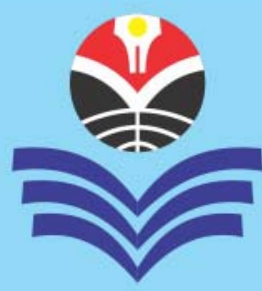

Published every March and September

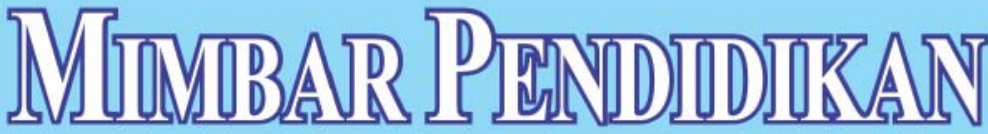

Jurnal Indonesia untuk Kajian Pendidikan

NORHASNI ZAINAL ABIDDIN \& AZAHARI ISMAIL

\title{
Peranan Fasilitator dalam Perbincangan Kumpulan Kelas: Ke Arah Pembangunan Pelajar di Institusi Pengajian Tinggi
}

\begin{abstract}
ABSTRAKSI: Perbincangan adalah pertukaran pendapat ataupun idea. Kaedah perbincangan kumpulan membolehkan pelajar berfikir secara konstruktif serta berkomunikasi dengan ahli kumpulan yang lain. Perbincangan menggalakkan pelajar untuk berinteraksi antara satu sama lain. Perbincangan menitikberatkan percakapan, pemerhatian, dan proses pendengaran. Perbincangan juga merupakan kaedah dimana pelajar dan fasilitator bertukar-tukar idea supaya mendapat pemahaman yang lebih mendalam mengenai sesuatu topik. Apabila kaedah perbincangan ini digunakan secara betul, ia merupakan cara yang baik untuk merangsang pemikiran pelajar. Terdapat pelbagai teknik perbincangan yang boleh digunakan (perbincangan panel, simposium, kajian kes, dan sebagainya). Setiap satunya mempunyai ciri-ciri yang unik. Perbincangan kumpulan boleh dijadikan salah satu teknik pengajaran didalam kelas bagi meningkatkan keyakinan pelajar dan juga pembangunan pelajar. Kecemerlangan pelajar tidak hanya tertumpu kepada pembangunan akademik sahaja, tetapi perlu dilihat dari segi sahsiah (kualiti diri dan kepimpinan). Pembangunan sahsiah amat penting dalam melahirkan pelajar yang berdisiplin, berfikir kreatif dan kritis, berkemahiran dalam berkomunikasi, serta berkemahiran dalam merancang dan membuat keputusan. Artikel ini mengupas peranan perbincangan kumpulan dalam pembangunan pelajar di institusi pengajian tinggi.
\end{abstract}

KATA KUNCI: Fasilitator, perbincangan kumpulan, pelajar, pembangunan akademik, dan sahsiah diri.

ABSTRACT: "The Role of Facilitator in Class Group Discussion: Towards Student Development in Higher Education Institution”. Discussion is an exchange of opinions or ideas. Group discussion methods are effective in getting the students to think constructively while interacting with the rest of the group. A true class discussion requires a student-to-student interchange of ideas. Discussion emphasizes on speaking, observing, listening process. The discussion method is one in which the trainees and the facilitator exchange their ideas in order to get a better understanding of a topic. The discussion method, when used properly, is a good way to stimulate thinking on the part of the student. There are varieties of discussion techniques that can be profitably used in conducting a training program (panel discussion, symposium, case study, etc). Each has unique characteristics and potential. Group discussion can be used as one of teaching techniques in classroom to enhance students' confidence level and personality development. Student development must be seen not only in terms of their academic performance, but also personality (self-quality and leadership). Personality development is important to create students with high discipline level, who are able to think creatively as well as think critically, excellent in communication, and competent in planning and decision making. This article elaborates group discussion in enhancing student development in higher education institutions.

KEY WORD: Facilitator, group discussion, student, academic performance, and personality development.

About the Authors: Assoc. Prof. Dato’ Dr. Norhasni Zainal Abiddin dan Assoc. Prof. Dr. Azahari Ismail ialah Pensyarah di Jabatan Pemajuan Profesional dan Pendidikan Lanjutan, Fakulti Pengajian Pendidikan UPM (Universiti Putra Malaysia), Serdang, Selangor Darul Ehsan, Malaysia. Alamat emel: nonieza99@gmail.com

How to cite this article? Abiddin, Norhasni Zainal \& Azahari Ismail. (2016). "Peranan Fasilitator dalam Perbincangan Kumpulan Kelas: Ke Arah Pembangunan Pelajar di Institusi Pengajian Tinggi” in MIMBAR PENDIDIKAN: Jurnal Indonesia untuk Kajian Pendidikan, Vol.1(1) Maret, pp.69-76. Bandung, Indonesia: UPI Press.

Chronicle of the article: Accepted (February 2, 2016); Revised (February 20, 2016); and Published (March 11, 2016). 


\section{PENDAHULUAN}

Dalam arus pembangunan yang semakin mencabar, pelajar seharusnya cemerlang tidak hanya dalam akademik, tetapi kecemerlangan pelajar zaman ini harus meliputi daya kualiti diri, khususnya bagaimana ia dapat menampilkan diri sebagai seorang pemimpin pada masa akan datang, termasuklah keunggulan dalam aspek sahsiah pelajar. Keunggulan sahsiah pelajar amat perlu diberikan perhatian bagi membolehkan mereka mengemblengkan dengan keintelektualan yang mereka miliki. Dengan penggabungan antara keintelektualan dan keunggulan sahsiah, negara akan memperolehi bakal pemimpin yang dinamik dan berintegriti. Integriti individu ialah keselarasan di antara apa yang dikatakan oleh individu dengan apa yang diamalkannya; keselarasan di antara tindakannya dengan prinsip moral, etika dan undang-undang; serta keselarasan di antara kepentingan diri dengan kepentingan umum.

Tingkah-laku manusia bergantung kepada pembelajaran yang diperolehinya ( $\mathrm{Hu} \&$ Kuh, 2003; dan Gaitan, 2012). Pembelajaran boleh berlaku di pelbagai tempat dan situasi. Peranan fasilitator adalah penting dalam merancang aktiviti atau pengajaran yang berkesan (Ismail et al., 2014). Justeru, sebagai fasilitator, pemilihan teknik atau kaedah latihan/pengajaran dilihat sebagai salah satu cara untuk meningkatkan pembangunan pelajar.

Pembangunan pelajar adalah tanggungjawab bersama antara sekolah, universiti, pensyarah, keluarga, masyarakat, dan juga pelajar itu sendiri. Pembangunan pelajar tidak dapat lari daripada pembelajaran (Abiddin \& Ismail, 2012). Perbincangan kumpulan dilihat sebagai salah satu teknik yang dapat diaplikasikan didalam kelas. Walau bagaimanapun, perancangan dan pelaksanaan yang teliti dapat membantu menjamin aktiviti ini dilakukan dengan efektif.

Jika dikaji objektif pendidikan berdasarkan tahap taksonomi B.S. Bloom (1956), fasilitator tidak lagi boleh mengharapkan objektif pembelajaran yang tertumpu kepada tahap atau aras rendah, seperti pengetahuan dan kefahaman ( $c f$ Bloom, 1956; dan CADE UPM, 2012). Tahap aplikasi, analisis, sintesis, dan penilaian perlu diterjemahkan kedalam aktiviti di kelas untuk mengoptimumkan pencapaian sahsiah pelajar. Maka itu, perlu wujudnya domain sosial yang memberi tumpuan kepada aspek pengurusan, kerja berpasukan, komunikasi, dan kepemimpinan.

Domain sosial ini amat baik untuk diwujudkan ketika pengendalian aktiviti kelas, kerana ia menjurus ke aras pembangunan pelajar itu sendiri. Justeru, artikel ini mengupas satu kaedah atau teknik latihan atau pengajaran yang dilihat dapat membantu ke arah pembangunan pelajar. Artikel ini memberi pendedahan umum bagaimana perancangan dan pengendalian perbincangan kumpulan seharusnya berlaku, peranan fasilitator dalam perbincangan kumpulan, masalah yang sering berlaku ketika perbincangan kumpulan, dan juga cara mengatasinya.

\section{PEMBANGUNAN PELAJAR}

Teori-teori berkaitan dengan pembangunan pelajar mengandungi pelbagai aspek yang dititikberatkan dalam setiap teori tersebut. Teori Psiko-Sosial, umpamanya, memberi fokus kepada isu yang panjang, yang mungkin akan berlaku berdasarkan umur, kemajuan pelajar dalam pelbagai peringkat kehidupan mereka (Arnett, 2000; dan Arnett \& Tanner eds., 2006).

Manakala Teori Cognitive-Structural pula memberi penekanan kepada bagaimana pelajar merasionalkan pengalaman mereka (King \& Baxter, 1996). Teori PersonEnvironment pula mengetengahkan tentang interaksi antara pelajar dengan persekitaran, dengan melihat kepada tingkah-laku sebagai fungsi sosial kepada individu dan juga persekitaran (King \& Baxter, 2005). Teori 
ini juga berkait rapat dengan perancangan kerjaya pelajar (Manke \& Erwin, 1988).

Teori Humanistic-Existential pula menumpukan kepada konsep dan filosifi tentang kejadian manusia, kebebasan, dan tanggungjawab, dimana pendidikan dan perkembangan diri individu adalah digalakkan oleh diri sendiri dan kesedaran kendiri. Teori ini banyak diguna-pakai dalam kaunseling (Pizzolato, 2008; dan Pizzolato et al., 2009).

Antara teori pembangunan pelajar yang terkenal adalah Teori Pembangunan Identiti oleh A.W. Chickering \& L. Reisser (1993); dan juga Teori Pembangunan Pelajar oleh W. Perry (1999). Pelbagai teori lain lagi banyak dijadikan panduan dalam aspek pembangunan pelajar.

Satu daripada model yang boleh dijadikan panduan dalam konteks artikel ini adalah Model Pembelajaran Pengalaman oleh D.A. Kolb (1984). D.A. Kolb melihat bagaimana individu itu belajar adalah satu perkara penting dalam pembangunan diri. Apabila seseorang itu mengetahui apa yang patut dilakukan untuk mereka belajar akan menjadikan sesorang itu mudah berkembang sebagai seseorang individu yang berjaya. Dengan menggunakan pelbagai jenis personaliti sebagai cara untuk belajar akan menjadikan seseorang itu sedar dan berkehendak untuk belajar dengan cara yang baru (Kolb, 1984).

Terdapat empat kitaran pembelajaran yang dinyatakan oleh D.A. Kolb (1984), iaitu: (1) Pengalaman konkrit-pelajar mendapat maklumat melalui pengalaman terus atau langsung; (2) Pemerhatian reflektif-pelajar memerhati; (3) Konseptual abstrak-pelajar mendapat maklumat secara pemahaman konsep dan prinsipal; dan (4) Eksperimentasi aktif-melakukannya (Kolb, 1984).

Proses pembelajaran ini dimulai apabila seseorang itu menerima maklumat secara pengalaman konkrit, iaitu ia benar-benar memahami dan merasai atau secara konseptual abstrak sahaja, iaitu individu itu berfikir secara bertentangan dengan apa yang diperolehinya. Pelajar seterusnya memproses maklumat tersebut secara pemerhatian reflektif, dengan memerhati atau secara eksperimentasi aktif dengan cara melakukannya sendiri. Pelbagai faktor mempengaruhi bagaimana pelajar memproses maklumat. Antara faktornya adalah latar belakang pendidikan, jenis personaliti, dan juga kerjaya yang diceburi (Kolb, 1984).

Teori pembelajaran pengalaman dari D.A. Kolb (1984) ini juga menyatakan bahawa idea dibentuk melalui pengalaman, yang mana pembelajaran merupakan satu proses yang sentiasa boleh diubah-suai berkadarkan pengalaman. Untuk menjadikan teori ini produktif kepada pembelajaran, pelajar perlu: (1) terlibat secara aktif dalam pembelajaran baru; (2) memerhati secara reflektif bagi menghubungkan pengalaman sedia ada kepada pemerhatian baru; (3) membentuk konseptual abstrak bagi membentuk teori dan generalisasi yang logik; dan (4) menggunakan pelbagai kaedah lain yang baru dalam membuat keputusan dan menyelesaikan masalah (Kolb, 1984).

Oleh yang demikian, dalam konteks pembelajaran, menerusi kaedah perbincangan kumpulan, ia amat selari dengan huraian teori D.A. Kolb (1984) yang dinyatakan di atas. Perbincangan kumpulan, secara dasarnya, adalah satu penghujahan dengan cara berbincang tentang kebaikan dan kelemahan sesuatu idea. Penghasilan idea dalam perbincangan kumpulan ada ketikanya berlaku secara efisyen, apabila masing-masing berusaha untuk memberikan idea. Justeru, kaedah pengajaran ini boleh mengguna-pakai kitaran pembelajaran oleh D.A. Kolb ini, sama ada melalui pengalaman konkrit, konseptual abstrak, pemerhatian reflektif, ataupun eksperimentasi aktif (Kolb, 1984).

\section{PERBINCANGAN KUMPULAN}

Tujuan. Terdapat dua tujuan utama dalam kaedah perbincangan. Pertama, perbincangan sepatutnya berfungsi dalam merangsang 
pelajar untuk berfikir secara kritikal dan kreatif. Kedua, perbincangan sepatutnya dapat mengembangkan kemahiran interaksi sosial pelajar.

Kepentingan perbincangan adalah untuk:

(1) mewajarkan sesuatu pendapat; dan

(2) menerima pandangan yang berbeza.

Perbincangan memberi pelajar peluang untuk mendapat penerangan, meneliti pemikiran sendiri, menilai idea, dan mensintesis pandangan sendiri. Pelajar juga mempunyai peluang untuk memikul tanggungjawab dengan mengambil alih peranan pemimpin dalam kumpulan.

Mengikut S. Pitner (2009), apa yang berlaku didalam kelas adalah situasi dimana fasilitator menyediakan topik perbincangan, manakala pelajar pula mereka buah fikiran fasilitator/pengajarnya. Daripada mengembangkan kemahiran interaksi sosial, pelajar hanya mencuba untuk menyenangkan hati fasilitator mereka. Dalam kelas seperti ini, perbincangan yang sebenar tidak berlaku. Pertukaran idea daripada fasilitator kepada pelajar, semasa sesi soal-jawab yang tipikal, tidak dianggap sebagai perbincangan (Pitner, 2009).

Menurut M. Markusic (2008), perbincangan tidak dapat diaplikasikan dalam semua situasi. Sebagai contoh, sekiranya terdapat lebih daripada 20 orang pelajar dalam satu kelas, perbincangan sepatutnya dijadikan opsyen strategi pengajaran yang terakhir. Sekiranya diadakan juga, hanya beberapa orang pelajar sahaja yang dapat melibatkan diri dalam perbincangan. Pelajar yang lain akan menjadi pasif atau bersikap acuh tak acuh terhadap topik yang dibincangkan (Markusic, 2008).

Perbincangan tidak sepatutnya dijalankan apabila fasilitator dan pelajar mempunyai kekangan masa. Oleh itu, perbincangan bukan teknik yang efektif untuk kelas ulangkaji. Perbincangan juga tidak seharusnya digunakan apabila fasilitator merancang untuk menghabiskan banyak topik dalam jangka masa yang pendek (Gugglberger et al., 2015).
Perancangan dan Persediaan. Untuk menjayakan perbincangan, bilik darjah perlu disusun supaya fasilitator menjadi sebahagian daripada kumpulan perbincangan. Seelokeloknya, ahli kumpulan duduk mengelilingi meja supaya mereka boleh melihat antara satu sama lain. Kaedah perbincangan hanya sesuai digunakan apabila bilangan pelajar cukup kecil, supaya semua pelajar berpeluang mengambil bahagian dalam perbincangan.

Perbincangan kumpulan kecil dapat dikawal dan diarah dengan lebih mudah berbanding dengan kumpulan besar yang melebihi 10 orang atau lebih, disyorkan lima sehingga enam ahli adalah saiz optimum untuk perbincangan kumpulan kecil. Sekiranya kumpulan terlalu besar, kumpulan tersebut sepatutnya dipecahkan kepada kumpulan atau pasukan yang lebih kecil, yang setiap satunya diketuai oleh seorang ketua perbincangan (Merrill, 2002).

Kumpulan yang terdiri daripada dua atau tiga orang ahli tidak memerlukan ketua, namun apabila terdapat lima atau enam orang ahli kumpulan, kehadiran seorang ketua ataupun fasilitator lebih membantu. Apabila terdapat lapan atau lebih ahli kumpulan, sama ada perbincangan dilakukan secara formal atau tidak formal, kehadiran seorang ketua atau fasilitator amat membantu untuk memastikan perbincangan yang berkesan.

Perbincangan yang berjaya tidak terjadi begitu sahaja. Perbincangan yang berjaya memerlukan fasilitator untuk membuat persediaan yang rapi. Antara perancangannya adalah: pertama, mendefinisikan objektif kumpulan perbincangan, memberitahu pelajar bahawa fasilitator tidak mengharapkan pelajar untuk bercakap setiap masa, fasilitator perlu menekankan bahawa pelajar tidak perlu menonjolkan kecemerlangan prestasi mereka, tetapi mereka perlu berkongsi pendapat serta pemerhatian mereka, adalah penting untuk fasilitator memahami perasaan gementar yang dialami oleh pelajar, pelajar perlu diyakinkan bahawa fasilitator 
tidak akan menilai setiap perkataan yang diungkapkan, selain itu perlu ditegaskan bahawa matlamat perbincangan adalah untuk mempertingkatkan kefahaman pelajar tentang sesuatu topik; kedua, menjelaskan format perbincangan kepada kelas, tukar format secara kerap untuk memastikan pelajar tidak hilang minat terhadap perbincangan; dan ketiga, mendefinisikan istilah dan andaian, peserta perbincangan mesti bersetuju terhadap definisi istilah dan andaian tentang sesuatu tajuk perbincangan, supaya semua pelajar mempunyai pemahaman yang sama.

Menurut P. Frederick (1981), untuk menghasilkan perbincangan yang berkesan, fasilitator sepatutnya: (1) Bertanyakan soalan: bertanya pelajar terlebih dahulu tentang hasil pembacaan mereka. Sebabsebab untuk bertanya soalan adalah untuk mengesan masalah-masalah yang dihadapi oleh pelajar, memperkenalkan topik, merangsang pemikiran analitikal, memberi bimbingan tentang penyelesaian masalah, menggalakan pemikiran imaginatif, dan membantu pelajar mencari hubungan antara konsep dan idea; serta (2) Memecahkan kelas kepada kumpulan yang lebih kecil: bahagikan kelas kepada pasangan atau kumpulan kecil dan meminta setiap kumpulan untuk mengajukan satu soalan penting kepada seluruh kelas. Kaedah ini hanya berkesan apabila pelajar diberi rangka tugasan yang jelas dan tempoh masa yang sesuai untuk melengkapkannya (Frederick, 1981). Latihan ini paling berjaya apabila pelajar bersedia lebih awal sebelum datang ke kelas.

Masih menurut P. Frederick (1981) lagi, untuk mengekalkan perbincangan, fasilitator perlu: (1) Mengawal peserta yang banyak bercakap: jangan membiarkan seorang atau dua peserta memonopoli perbincangan. Jangan memanggil peserta yang banyak bercakap terlebih dahulu. Tunggu dan lihat, sama ada terdapat peserta lain yang sudi mengangkat tangan atau memberi komen secara sukarela. Fasilitator perlu mendapatkan maklum-balas daripada peserta yang tidak bercakap dan memberi perhatian terhadap isyarat bukan lisan, yang menunjukan bahawa peserta tersebut mempunyai sesuatu untuk dikatakan; dan (2) Perbincangan yang terpesong: berhenti seketika dan meminta pelajar untuk meringkaskan setakat mana yang dibincangkan bagi membantu kumpulan untuk fokus semula (Frederick, 1981).

Peranan Fasilitator. Berikut merupakan peranan fasilitator dalam sesi perbincangan. Pertamanya, mengenali pelajar. Mulakan perbincangan dengan topik yang pelajar boleh kaitkan dengan diri mereka, kemudian wujudkan tajuk perbincangan utama. Fasilitator perlu menggalakan pelajar yang pasif untuk bersuara dan menetapkan batasan untuk mereka yang terlalu banyak bercakap.

Keduanya, bersabar. Fasilitator perlu cuba untuk tidak memonopoli perbincangan. Ketiganya, dengar. Perbincangan kurang bermanfaat sekiranya fasilitator tidak mendengar sumbangan idea pelajar. Bersedia untuk menerima idea yang tidak tepat. Kata-kata "Tidak” atau “Anda salah!” boleh menamatkan perbincangan dengan cepat. Keempatnya, elakan daripada menyoal seorang pelajar dengan terlalu lama. Jika pelajar tidak memberi respon terhadap soalan, elakan daripada memalukan individu tersebut dengan terus menyoal.

Kelimanya, gunakan pengalaman peribadi. Berkongsi pengalaman diri sendiri boleh memudahkan perbincangan. Keenamnya, menyiasat. Minta pelajar untuk menghuraikan, menjelaskan, mengembangkan idea, dan meneroka tentang sesuatu perkara. Bertanya soalan yang merangsang pemikiran pelajar. Bertanya soalan juga boleh mengelakan perbincangan daripada terpesong dan memandu perbincangan ke arah kesimpulan yang diingini.

Ketujuhnya, meringkaskan idea. Adalah penting bagi fasilitator untuk meringkaskan idea, membuat kesimpulan tentang tajuk perbincangan. Ini membantu 
Jadual 1:

Masalah dalam Sesi Perbincangan dan Cara Mengatasinya

\begin{tabular}{|c|c|}
\hline Masalah dalam Sesi Perbincangan & $\begin{array}{l}\text { Sebagai seorang Fasilitator, } \\
\text { Bagaimana untuk Mengatasi Masalah ini? }\end{array}$ \\
\hline $\begin{array}{l}\text { - Terdapat kumpulan perbincangan yang akan } \\
\text { habis awal berbanding dengan kumpulan lain, } \\
\text { oleh itu banyak masa dibazirkan (David, 1995). }\end{array}$ & $\begin{array}{l}\text { - Bersiap sedia dengan tugasan tambahan seperti soalan } \\
\text { tambahan ataupun meminta pelajar untuk pergi ke } \\
\text { hadapan dengan menulis jalan penyelesaian pada papan } \\
\text { putih. }\end{array}$ \\
\hline $\begin{array}{l}\text { - Ada kalanya terdapat pelajar yang tidak } \\
\text { menyumbang idea langsung. }\end{array}$ & $\begin{array}{l}\text { - Ini merupakan tanda kumpulan yang tidak berfungsi. } \\
\text { Fasilitator perlu memberi bimbingan. }\end{array}$ \\
\hline $\begin{array}{l}\text { - Kaedah perbincangan akan membantutkan } \\
\text { perkembangan pelajar yang cemerlang } \\
\text { dan membolehkan pelajar yang lemah } \\
\text { untuk “mengambil kesempatan” (Heller \& } \\
\text { Hollabaugh, 1992; dan Carolyn \& Brian, 1996). }\end{array}$ & $\begin{array}{l}\text { - Kajian menunjukan bahawa perbincangan mampu } \\
\text { membantu pelajar, kerana pelajar cemerlang dapat } \\
\text { “mengajar” dan pelajar yang lemah mendapat } \\
\text { “bimbingan daripada rakan sekelas”. }\end{array}$ \\
\hline $\begin{array}{l}\text { - Kaedah perbincangan bersifat autoritatif, kerana } \\
\text { memaksa semua pelajar untuk bekerjasama, } \\
\text { walaupun mereka tidak mahu (Gardner, 2006). }\end{array}$ & $\begin{array}{l}\text { - Kaedah perbincangan menghormati pemikiran pelajar } \\
\text { yang pelbagai. Perbincangan memberi peluang kepada } \\
\text { pelajar untuk mengenal pasti pemikiran mereka. }\end{array}$ \\
\hline $\begin{array}{l}\text { - Pelajar tidak suka memikul tanggungjawab } \\
\text { dalam sesebuah kumpulan perbincangan (Davis } \\
\text { \& Wilcock, 2003). }\end{array}$ & $\begin{array}{l}\text { - Dalam perbincangan yang efektif, peranan atau } \\
\text { tanggungjawab wujud secara semula jadi dan bertukar- } \\
\text { tukar antara pelajar. Peranan ini membantu pelajar } \\
\text { yang tidak mahu bekerjasama untuk belajar berbuat } \\
\text { demikian. }\end{array}$ \\
\hline $\begin{array}{l}\text { - Pelajar tidak mahu bekerja dalam kumpulan } \\
\text { kerana mereka percaya bahawa mereka dapat } \\
\text { belajar dengan lebih baik secara sendiri (David, } \\
\text { 1995; dan Davis \& Wilcock, 2003). }\end{array}$ & $\begin{array}{l}\text { - Untuk belajar sesuatu dengan betul dan luas, } \\
\text { pelajar perlu bertukar-tukar idea dengan orang lain. } \\
\text { Pembelajaran adalah gabungan refleksi individu dan } \\
\text { interaksi kumpulan. Apabila pelajar sudah dapat } \\
\text { membiasakan diri, kebanyakan pelajar lebih suka untuk } \\
\text { bekerja dalam kumpulan. }\end{array}$ \\
\hline
\end{tabular}

untuk memastikan setiap fasilitator mengikuti perkembangan idea dan memahami perbincangan secara berterusan. Meringkaskan idea perbincangan juga dapat mengelakan fakta yang mengelirukan dan berlaku salah faham dalam kalangan pelajar.

Kelapannya, menghubung-kaitkan konsep dan idea. Fasilitator boleh meminta pelajar untuk membandingkan idea atau konsep yang dikemukakan dalam perbincangan, atau menggunakan analogi untuk mengaitkan idea tersebut. Dan akhir sekali, kesembilannya, bersifat terbuka dan tidak tergesa-gesa untuk membuat penilaian. Fasilitator perlu memberi tumpuan terhadap maklum-balas pelajar ( $c f$ Gangel, 2003; Manktelow \& Carlson, 2010; Williams, 2010; Burke, 2011; Laskowski, 2012; dan Sebastian \& Allensworth, 2012).

Masalah dalam Sesi Perbincangan Kumpulan dan Cara Mengatasinya. Jadual
1 menunjukan masalah yang sering dihadapi ketika sesi perbincangan berlangsung dan cara mengatasinya bagi meningkatkan keberkesanan kaedah perbincangan.

\section{KESIMPULAN}

Kualiti pelajar bergantung kepada kualiti sahsiah dan integriti pelajar itu sendiri. Pelajar sekarang adalah generasi penyambung yang membentuk kualiti negara masa hadapan. Pelajar adalah modal insan atau aset negara yang perlu dipelihara dan ditambah nilai kualitinya, kerana mereka adalah penyambung generasi kepimpinan. Rupa-bentuk dan corak masa depan negara bergantung kepada acuan pembangunan sumber manusia semasa. Pelbagai cara dapat dikendalikan dalam mencapai matlamat membangunkan pelajar ini. Fasilitator/pengajar, terutamanya di institusi pengajian tinggi, juga dapat membantu dengan mewujudkan teknik pengajaran 
yang bersesuaian bagi tujuan membangunkan sahsiah pelajar dan juga akademik pelajar.

Perbincangan kumpulan dilihat sebagai salah satu kaedah atau teknik latihan atau teknik pengajaran yang sesuai diguna-pakai dalam mengendalikan kelas atau kuliah bagi tujuan ini. Perbincangan kumpulan digunakan atas sebab berikut, iaitu: (1) digunakan untuk aktiviti penyelesaian masalah; (2) untuk membangkitkan minat pelajar terhadap topik; (3) bagi tujuan mengguna-pakai pengetahuan dan idea-idea pelajar; (4) bagi mendorong pembelajaran yang lebih kekal, kerana tahap penglibatan pelajar yang tinggi; (5) untuk menentukan pemahaman dan kemajuan pelajar; dan (6) untuk memberi peluang bagi setiap pelajar melibatkan diri.

Sebagai fasilitator, perancangan dan pelaksanaan perbincangan kumpulan tidak harus dipandang remeh, kerana perancangan yang teliti dan pengendalian yang sempurna dapat membantu keberkesanan pembelajaran didalam kelas dan seterusnya mampu melahirkan pelajar yang mempunyai sahsiah yang tinggi. Perbincangan yang efektif dan sistematik tidak dapat disangkal lagi dapat memberi kesan yang signifikan kepada pembangunan pelajar dan pembangunan sumber manusia secara amnya. ${ }^{1}$

\section{Referensi}

Abiddin, N.Z. \& A. Ismail. (2012). "Exploring Student Development Theory in Enhancing Learning Through Supervision” dalam International Journal of Academic Research in Progressive Education and Development, 1(1), ms.213-223.

Arnett, J.J. (2000). “Emerging Adulthood: A Theory of Development from the Late Teens Through the Twenties” dalam American Psychologist, 55(5), ms.469-480.

\footnotetext{
${ }^{1}$ Kenyataan: Dengan ini, kami membuat kenyataan bahawa artikel ini adalah merupakan dapatan pemikiran dan penyelidikan kami berdua. Ianya bukan dapatan daripada amalan plagiarism, sebab sumber-sumber yang kami petik jelas wujud dalam senarai Rujukan. Kertas ini juga belum dinilai dan belum diterbit oleh mana-mana jurnal akademik, samada di Malaysia mahupun di luar negara.
}

Arnett, J.J. \& J.L. Tanner [eds]. (2006). Emerging Adulthood: Coming of Age in the $21^{\text {st Century }}$. Washington, DC: American Psychological Association.

Bloom, B.S. (1956). Taxonomy of Educational Objectives, Handbook: The Cognitive Domain. New York: David McKay Co, Inc.

Burke, A. (2011). “Group Work: How to Use Groups Effectively” dalam The Journal of Effective Teaching, 11(2), ms.87-95.

CADE UPM [Center of Academic Development, University of Putra Malaysia]. (2012). "Domain Pembelajaran”. Wujud secara online pula di: http:// cade.upm.edu.my/v2012/ [diakses di Serdang, Malaysia: 8hb Januari 2016].

Carolyn B. \& H.K. Brian. (1996). “Advantages and Disadvantages of Group Decision- Making Approaches” dalam Management Development Review, 2(1), ms.30-35.

Chickering, A.W. \& L. Reisser. (1993). Education and Identity. San Francisco, CA: Jossey-Bass.

David, H. (1995). Improving Discussions. Kansas, USA [United States of America]: Center for Faculty Evaluation \& Development KSU [Kansas State University].

Davis, C.L. \& E. Wilcock. (2003). Case Study Teaching. UK [United Kingdom]: UK Centre for Materials Education.

Frederick, P. (1981). “The Dreaded Discussion: Ten Ways to Start” dalam Improving College and University Teaching, 29(3), ms.109-114.

Gaitan, A. (2012). “Understanding Students' Experiences of e-PDP and the Factors that Shape Their Attitudes” dalam International Journal of e-Portfolio, 2(1), ms.29-38.

Gangel, K.O. (2003). 24 Ways to Improve Your Teaching. Oregon: Wipf Stock Publishers.

Gardner, H. (2006). The Development and Education of the Mind: The Collected Works of Howard Gardner. London: Routledge.

Gugglberger, L. et al. (2015). “The Use of Group Discussions: A Case Study of Learning about Organisational Characteristics of Schools" dalam International Journal of Social Research Methodology, 18(2), ms.127-143.

Heller, P. \& M. Hollabaugh. (1992). “Teaching Problem Solving Through Cooperative Grouping, Part 2: Designing Problems and Structuring Groups” dalam American Journal of Physics, 60(7), ms.637-644.

Hu, S. \& G.D. Kuh. (2003). "Diversity Experiences and College Student Learning and Development” dalam Journal of College Student Development, 44(3), ms.320-334.

Ismail, A. et al. (2014). "The Profound of Students' Supervision Practice in Higher Education to 
Enhance Student Development” dalam Higher Education Studies, 4(4), ms.1-6.

King, P.M. \& M.M.B. Baxter. (1996). “A Developmental Perspective on Learning” dalam Journal of College Student Development, 37(2), ms.163-173.

King, P.M. \& M.M.B. Baxter. (2005). “A Developmental Model of Intercultural Maturity” dalam Journal of College Student Development, 46(6), ms.571-592.

Kolb, D.A. (1984). Experiential Learning as a Source of Development. New Jersey: Prentice Hall.

Laskowski, L. (2012). Painless Presentations: The Proven, Stress-Free Way to Successful Public Speaking. New York: John Wiley \& Sons.

Manke, M.P. \& T.D. Erwin. (1988). “Meta-Analysis: Summarizing Student Development Literature Quantitatively” dalam Journal of College Student Development, 29(6), ms.549-562.

Manktelow, J. \& A. Carlson. (2010). Brainstorming Technique. London: Mind Tools.

Markusic, M. (2008). “Classroom Instruction: The Discussion Technique”. Wujud secara online pula di: http://www.brighthub.com/education/special/ articles/5481.aspx [diakses di Serdang, Malaysia: 8hb Januari 2016].

Merrill, M.D. (2002). “First Principles of Instruction” dalam Educational Technology Research and Development, 50(3), ms.43-59.
Perry, W. (1999). Forms of Intellectual and Ethical Development in the College Years: A Scheme. San Francisco, California: Jossey-Bass Publishers, $1^{\text {st }}$ edition.

Pitner, S. (2009). "Create a Comfortable Learning Space to Maximize Student Productivity”. Wujud secara online pula di: http://classroomorganization. suite101.com/article.cfm/how to plan a classroom_seating_arrangement [diakses di Serdang, Malaysia: 8hb Januari 2016].

Pizzolato, J.E. (2008). “Meaning-Making Inside and Outside the Academic Arena: Investigating the Contextuality of Epistemological Development in College Students" dalam The Journal of General Education, 56(3-4), ms.228-251.

Pizzolato, J.E. et al. (2009). "Student Development, Student Learning: Examining the Relation between Epistemologic Development and Learning” dalam Journal of College Student Development, 50(5), ms.475-490.

Sebastian, J. \& E. Allensworth. (2012). “The Influence of Principal Leadership on Classroom Instruction and Student Learning: A Study of Mediated Pathways to Learning” dalam Educational Administration Quarterly, 48, ms.626-663.

Williams, R. (2010). Open Educational Resources Task Force. Florida: FSU [Florida State University]. 